Berkeley Law

From the SelectedWorks of Robert Cooter

June, 1984

\title{
Personal versus Impersonal Trade: The Size of Trading Groups and Contract Law
}

Robert D. Cooter 


\title{
PERSONAL VERSUS IMPERSONAL TRADE: THE SIZE OF TRADING GROUPS AND CONTRACT LAW
}

\author{
ROBERT COOTER
}

Law School, University of California at Berkeley, Berkeley CA 94720, USA

AND

JANET T. LANDA

Department of Economics, York University, 4700 Keele Street, Downsview, Ontario M3J 1P3, Canada

\section{INTRODUCTION}

The economic model of perfect competition depicts exchange as occurring between anonymous partners. Trade is anonymous because buyers and sellers are indifferent as to the identity of their trading partners. This characteristic of competitive exchange, sometimes called Jevons' Law of Indifference, ${ }^{1}$ is implicit in the idea that commodities are homogeneous and traders care only about price.

In reality, trade often occurs between people who know each other personally. Personal knowledge is important because trade often involves contracts, rather than the simultaneous exchange of goods and money. A contract always involves a promise: a good is given in exchange for a promise to pay, money is given in exchange for a promise to deliver a good, or one promise is exchanged for another. The reliability of a person's promise is important when considering whether to contract with him, especially if contract law is weak or undeveloped.

In underdeveloped countries, personal trading relations often take the form of ethnically homogeneous trading groups, such as the East Indians in East Africa, the Syrians in West Africa, the Chinese in Southeast Asia, and the Jews in medieval Europe. Landa developed a theory of ethnically homogeneous Chinese middlemen as a club-like arrangement for the enforcement of contracts in conditions of uncertainty. ${ }^{2}$ Carr and Landa generalized this theory. ${ }^{3}$ Central to it is the idea that a trader will discriminate among potential partners in order to economize on the cost of enforcing contracts. Thus private trading groups are a substitute for public laws regulating contracts.

In this paper we develop a theory about the relationship between the size of trading groups and the development of the law of contracts. It is easy to summarize our model and its conclusions. We think of a trading group as a repository of trust which reduces the probability of breach on a contract between insiders. If the group expands, then members gain the advantage of a more extensive internal market. The advantage of a more extensive internal market is that it permits greater diversity of trade within the group. On the other hand, as the group expands, personal relations become attenuated. Personal relations enable the group to rely upon 
informal means of enforcement of contracts. If the group becomes quite large, formal methods of enforcement, which are more costly than informal methods, will have to be adopted to enforce contracts. In other words, for a given level of expenditure by the group on enforcement, the probability of breach will increase as the group becomes larger. Thus there will be a tradeoff between diversity of trade within the group and security of contracts.

Group members enjoy profits from exchange. By definition, the representative group member enjoys the average level of profits within the group. There is some size of the group which is best from the viewpoint of a representative member, and there is some size which is best from a social viewpoint which takes account of members and non-members. We prove that these sizes are not the same. To be more precise, assuming that charging a discriminatory membership fee is impossible, the size of the group which maximizes profits for the representative member is smaller than the size which maximizes the total profits of members and non-members. This conclusion is similar to the standard result that a non-discriminating monopolist supplies too little of a good.

The actual size which a trading group attains will depend in part upon who controls admission to it. If the person controlling admission maximizes average profits, which would occur if admissions policies were set by the representative member, then the club would be too small. Taking the argument to the opposite extreme, if the group must freely admit everyone who applies, then it will be too large relative to the social optimum. Free entry results in too large a group because new entrants treat the pool of trust as a free resource. Thus the argument that free entry results in too large a group is analogous to the conclusion that free entry into a public facility results in excessive congestion.

Taken together, the two preceding paragraphs suggest that an economy will be inefficient if trading groups are unrestricted or if they are forced to accept everyone. Fortunately, our analysis also suggests an alternative to the extreme policy options of forcing an exclusive group to accept everyone or doing nothing. We also prove that membership in clubs will decline if contracts with outsiders become more secure. Thus, the monopoly power and influence of exclusive clubs can be attacked indirectly by increasing the effectiveness of contract law.

Having summarized our model, we now develop it formally.

\section{THE MATHEMATICAL MODEL}

Consider an exchange economy in which trade occurs through contracts and there is a positive probability that any contract will be breached without compensation. For simplicity, assume that all potential trading partners can be classified into two groups: insiders (club members) and outsiders (non-members). We will use Roman letters to denote variables concerning insiders, and Greek letters to denote variables concerning outsiders. The probability of performance on a contract between insiders is denoted $p$, so the probability of breach is $1-p$. The probability of performance on a contract between an insider and an outsider is denoted $\pi$, so the probability of breach is $I-\pi$. For simplicity, the latter probability is assumed to be the same as the probability of breach between two outsiders. The probability of insider breach is assumed to be lower than outsider breach: $p>\pi$.

Performance on a contract between insiders produces value $v$ for each party to it. Performance on a contract between an insider and an outsider, or between two outsiders, produces value $\gamma$ for each party to it. Without loss of generality, we 
assume that the payoff from breach of a contract is nil. Thus the expected value of an insider contract is $p v$ and the expected value of an outsider contract is $\pi \gamma$.

Insiders divide their trade between other insiders and outsiders. Let $t$ denote the number of trades that a representative insider conducts with other insiders, and let $1-t$ denote his trades with outsiders. Thus the expected payoff which a representative insider enjoys from exchange is

$$
V=t p v+(1-t) \pi \gamma
$$

The probability $p$ of performance on an insider contract decreases with the number of insiders, $p=p(i)$ where $p<0$, since contract enforcement becomes more costly as the club increases in size. The probability $p$ decreases with club size $i$ because informal methods of social control become less effective as personal relations are attenuated. Expenditure on formal methods of contract enforcement are held constant implicitly. However, the average payoff $v$ from performance on an insider contract increases with the number of insiders $i$, because more insiders permit more variety in the goods exchanged. For the same reason, the average payoff $v$ decreases when a larger proportion of the total trades $t$ are conducted among insiders:

$$
v=v(i, t) \text { where } v_{1}>0 \text { and } v_{2}<0
$$

Substitution of terms into the equation for $V$ gives the expected payoff which a representative insider enjoys from the trade:

$$
V=t p(i) v(i, t)+(1-t) \pi \gamma
$$

The monopoly club chooses $i$ and $t$ to maximize $V$.

The total value of all exchanges in the economy is the sum of payoffs to all insiders and outsiders $I$ :

$$
W=i V+(I-i) \pi \gamma
$$

The socially efficient club membership is the value of $i$ which maximizes $W$.

Let $i^{*}(t)$ indicate the values of $i$ which maximize $W$ relative to $t$. Under the usual continuity and convexity assumptions, this function can be found by solving the first order condition

$$
0 \geq \frac{\partial W}{\partial \mathrm{i}}=(V-\pi \gamma)+i \frac{\partial V}{\partial i}
$$

The analytically interesting case concerns a situation in which club membership is not a disadvantage: $V \geq \pi \gamma$. This assumption and Eq. 3 imply that $0 \geq \frac{\partial V(i, t)}{\partial i}$ for all $t$, evaluated at $i=i^{*}(t)$.

It is helpful to graphically represent the relationship between $W$ and $V$. Define $i_{m}(t)$ to be the values of $i$ which maximize $V$ relative to $t$. This function can be found by solving

$$
0 \geq \frac{\partial V(i, t)}{\partial i}
$$


In the preceding paragraph we showed that $0 \geq \frac{\partial V(i, t)}{\partial i}$ at $i=i^{*}(t)$ and $0 \geq \frac{\partial W(i, t)}{\partial i}$ at $i=i^{*}(t)$, with a strict equality for internal maxima. This fact and the convexity assumptions imply that the functions have the characteristics depicted in Figure 1. This graph is essential in the arguments which follow.

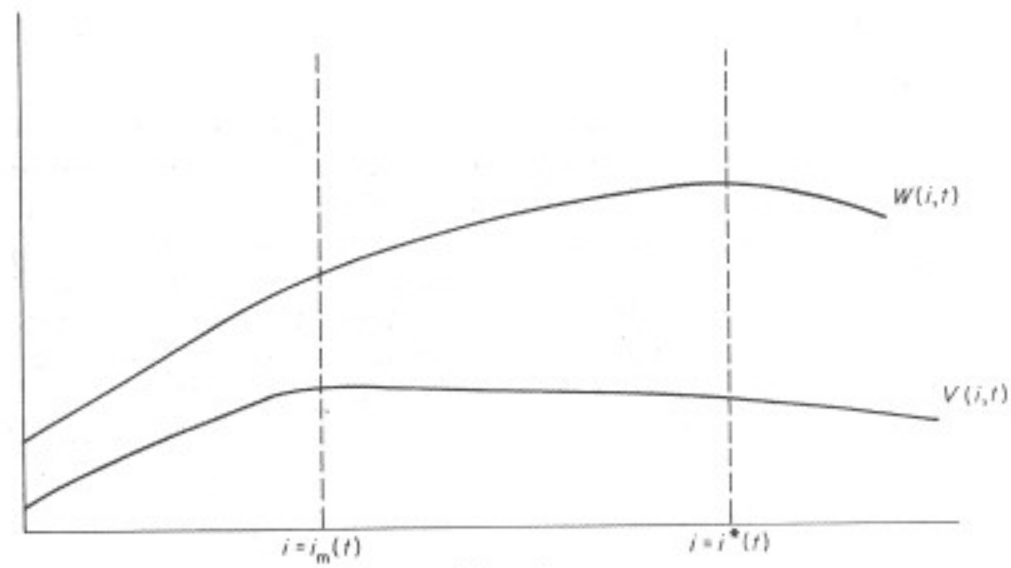

FIG. I.

We will discuss conditions under which private bargaining will result in the socially efficient club membership. Then we prove that free entry and monopoly control will not ordinarily result in efficient membership. These proofs make the usual convexity and continuity assumptions, i.e., controls can be approximated by continuous variables, first- and second-order derivatives exist, and the second-order conditions for optima are satisfied.

\section{Perfect bargaining}

It is possible to imagine different rules for admission to the club. One possibility is that non-members have the right to admission, in which case we say that there is free entry. Another possibility is that the original members control admission of new members, in which case we say that there is monopoly.

If the number of members is inefficiently small, then the total value of trades can be increased by admitting additional members. There is a tradition in economics of assuming that gains from trade will be exhausted if bargaining is costless. ${ }^{4}$ This tradition leads to the conclusion that costless bargaining between members and nonmembers will lead to an efficient number of members, regardless of whether the background rule is free entry or monopoly. This proposition corresponds to the familiar Coase Theorem, which asserts that efficiency will be achieved, regardless of the rule of liability, providing that the parties affected by a legal right can bargain costlessly.

For example, suppose that the original club member can set an initiation fee which new members must pay. Non-members would be willing to join so long as the initiation fee did not exceed the value of membership. These assumptions correspond to a perfectly discriminating monopolist, who will achieve the efficient club size, as we now show. 
The value which a non-member places upon admission to the club equals the difference in payoffs between insiders and outsiders, or $V-\pi \gamma$. Think of the original member as collecting the admission fee $V-\pi \gamma$ from all $i$ members, except himself. Thus, the controlling member enjoys the payoff from membership $V$, plus the initiation fees $(V-\pi \gamma)$, paid by $i-1$ people:

$$
\begin{aligned}
\text { discriminating monopolist's payoff } & =V+(i-1)(V-\pi \gamma) \\
& =i(V-\pi \gamma)+\pi \gamma
\end{aligned}
$$

The total value of trade is given by Eq. 2, which can be written

$$
W=i(V-\pi \gamma)+I \pi \gamma
$$

Thus the total value of trade and the discriminating monopolist's payoff differ with respect to the terms $\pi y$ and $I \pi y$. These terms are constant with respect to $i$ and $t$, so the difference between the equations does not affect the maximizing values of $i$ and $t$. Thus the discriminating monopolist chooses the club size which maximizes the social value of trade.

The discriminating monopolist bargains with each individual to arrive at the initiation fee $V-\pi \gamma$. The impediments to such bargaining include the cost of enforcing contracts, which motivates this paper. We are interested primarily in the situation where members and non-members cannot bargain together in order to achieve an efficient club size, so we now turn to examine free entry and monopoly without bargaining.

\section{Monopoly}

Suppose that the original members of the club control entry, but there is no discriminatory initiation fee. Power and authority might be distributed in various ways among club members. A useful focal point for analysis is to assume that power is distributed so that the policy towards applicants to the club benefits the representative member. For example, this result would occur under a democratic organization in which profits are equally distributed among members, and existing members control the number of new members. This is just one illustration of why the club which controls its own admissions might maximize profits per member. It is easy to prove that under this assumption the monopoly club size, $i_{m}$, is too small relative to the social optimum, i.e., an increase in members would increase social value $W$.

This proposition follows immediately from the interpretation of Figure 1 . The monopoly membership is set at the value of $i=i_{m}(t)$, where $\frac{\partial V}{\partial i}=0$. At this point it is apparent that $\frac{\partial W}{\partial i}>0$, so increasing members would increase social value $W$.

The restriction on membership under monopoly is to be expected since the club does not take account of the difference between insider and outsider payoffs $(V-\pi \gamma)$ when deciding whether to admit an additional member. Instead, the club decides to admit a new member if and only if his membership will increase the payoff $V$ to insiders. 


\section{Free entry}

Suppose that anyone who wishes to join the club must be admitted on the same terms as existing members. We are contemplating a situation in which membership is, in effect, a property right of non-members, rather than a right of members as in the monopoly case. Under this assumption it is easy to prove that club membership will be too large, i.e., a decrease in the number of members would increase social value $W$. The reason why club membership is too large under free entry is that trust is treated as a free resource, so it is spread too thinly.

Under free entry, the payoff to insiders and outsiders is the same in equilibrium: $V(i, t)=\pi \gamma$. Let $i_{f}(t)$ be the values of $i$ which satisfy this equation. The derivative of $W$ with respect to $i$ is given by the equation

$$
\frac{\partial W(i, t)}{\partial i}=V-\pi \gamma+i \frac{\partial V}{\partial i}
$$

If $i=i_{j}(t)$, then

$$
\frac{\partial W(i, t)}{\partial t}=i \frac{\partial V}{\partial i}
$$

i.e., the derivative of $W$ and $V$ has the same sign. From Figure 1, it is clear that either $i_{f}(t)<i_{m}(t)$ or else $i_{f}(t)>i^{*}(t)$.

It is easy to see that $i_{f}(t)<i_{m}(t)$ implies an unstable free entry equilibrium. To see why, assume that $V=\pi \gamma$ and $i_{f}(t)<i_{m}(t)$. In this zone $\frac{\partial V}{\partial i}>0$, as depicted in Figure 1, so if an additional person joined the club, the equality would be changed to the inequality $V>\pi v$. But now everyone would want to join the club. Thus stability in the free entry equilibrium rules out the situation where $i_{f}(t)<i_{m}(t)$.

The remaining alternative is $i_{f}(t)>i^{*}(t)$, which is what we sought to prove. Thus the only stable free entry equilibrium (and all equilibria are stable under the convexity assumptions) is one in which membership is too large relative to the efficient level $i^{*}(t)$.

\section{Contract law}

We have shown that club size is too large under free entry and too small under nondiscriminating monopoly. Next we show that, under certain assumptions, club size falls when there is an improvement in the law of contract regulating exchange between non-members, regardless of the rule governing admission.

Suppose that the club is a non-discriminatory monopoly. An additional member causes the average value of performance on an insider contract to increase $\left(V_{2}>0\right)$. The average value of performance on an insider contract increases because an additional insider increases the variety of goods attainable within the club. However, an increase in $i$ causes insider breach to increase $\left(p^{\prime}<0\right)$. These two influences exactly of fset each other in monopoly equilibrium, so $V$ does not change if there is a small increase in $i$. However, an increase in the expected value of an outsider contract $(\pi y)$ will cause a decrease in insider trades $t$. As a consequence, the need for a large club to supply a diversity of goods will be diminished and the monopoly club size will fall. 
It is straightforward to prove this mathematically. The first-order conditions for a maximum by the monopoly club can be written

$$
\begin{aligned}
& 0=V_{1}(i, t) \\
& 0=V_{2}(i, t)
\end{aligned}
$$

Fully differentiate and invert to obtain:

$$
\left[\begin{array}{l}
d i \\
d t
\end{array}\right]=\frac{1}{\Delta}\left[\begin{array}{rr}
V_{22} & -V_{21} \\
-V_{12} & V_{11}
\end{array}\right]\left[\begin{array}{l}
0 \\
d(\pi \gamma)
\end{array}\right]
$$

where $\Delta$ is the determinant. Solve in order to obtain:

$$
\begin{aligned}
\frac{d t}{d(\pi \gamma)} & =\frac{1}{\Delta} V_{11} \\
& <0 \text { by second-order condition } \\
\frac{d i}{d(\pi \gamma)} & =\frac{-1}{\Delta} V_{21} \\
& =\left[\frac{-1}{\Delta}\right] \frac{\left\{p^{\prime} v+p v_{1}\right.}{0 \text { by } 0=V_{1}}+\frac{t p^{\prime} v_{2}}{+}+\frac{\left.t p v_{21}\right\}}{?}
\end{aligned}
$$

The first equation states that an increase in the expected value of outsider contracts $\pi \gamma$ causes insider trades $t$ to diminish. The second equation states that an increase in the expected value of outsider contracts $\pi \gamma$ causes the monopoly club to decrease in size, assuming $V_{21}$ is positive or small.

\section{CONCLUDING REMARKS}

We have shown that the socially efficient trading group is smaller than the free entry trading group and larger than the monopoly trading group which maximizes benefits to its representative member. These propositions may explain in part the behavior of trading groups and the reaction of governments to them. Successful trading groups in underdeveloped countries monopolize trade by erecting barriers to entry into the businesses which they control. These entry barriers may take the form of membership criteria such as ethnic identity, dietary restrictions, and religious rituals. These practices prevent entry by outsiders or raise its cost, and also lower the cost of identifying members and enforcing contracts among insiders. Part of the hostility of outsiders towards trading groups may be explained by the losses created by monopoly restrictions on entry. This hostility sometimes provokes harsh measures to destroy the monopoly power or expel the 'foreign' middlemen, e.g., the Chinese in Indonesia in the 1960s and the East Indians in Uganda in the 1970s.

According to the model in this paper, trading groups perform the useful function of facilitating contracts under conditions of uncertainty. Destroying the groups will inhibit trade. An alternative policy is to try to reduce the exclusiveness of groups. For example, the government of Singapore since the 1970s has encouraged the five major Chinese ethnic groups to use English and Mandarin Chinese in their dealings 
with each other in order to create a homogeneous society and facilitate foreign trade. This paper suggests still another approach to the problem, specifically developing and strengthening contract law. Improvements in contract law reduce the equilibrium size of trading groups by facilitating exchange among strangers. In brief, competitive conditions can be created by developing a legal structure in which anonymous exchange is not so risky.

Our analysis was carried out with a number of mathematical restrictions, e.g., the total number of trades and traders was fixed, and the only differentiation among traders was between insiders and outsiders. Relaxing these restrictions probably would not involve a fundamental change in the mathematics or conclusions. A more radical generalization would make the number of trading groups endogenous, not just their size.

\section{REFERENCES AND NOTES}

1. W. S. Jevons, Theory of Political Economy, (1871), Kelly and Millman (1957).

2. J. Landa, 'A Theory of the Ethnically Homogeneous Middleman Group: An Institutional Alternative to Contract Law,' (1981) 10 J. Legal Stud. 349.

3. J. Carr and J. Landa, 'The Economics of Symbols, Clan Names and Religion,' (1983) 12 J. Legal Stud. 135.

4. R. H. Coase, 'The Problem of Social Cost,' (1960) 3 J. Law and Econ. 1. R. Cooter, 'The Cost of Coase,' (1982) 11 J. Legal Stud. 1. 